\title{
Subsidiarity and Robustness: Building the Adaptive Efficiency of Federal Systems
}

\author{
Jenna Bednar* \\ University of Michigan \\ jbednar@umich.edu
}

Forthcoming, NOMOS (2014)

\begin{abstract}
Subsidiarity - a systemic predilection for locating authority at the most local level feasible - has long been admired for its ability to protect localized, diverse interests from the tyranny of a national majority. In this article I suggest a novel benefit of subsidiarity: it boosts the adaptive efficiency of federal systems. To remain relevant, federal systems must adapt to meet changing circumstances. The process of adaptation involves both pushing federalism's boundaries in search of improved national-state balance, and selecting beneficial changes and rejecting harmful ones, a job most efficiently conducted by a set of diverse, complementary safeguards. By drawing a distinction between policy subsidiarity and safeguard subsidiarity, I describe how each form of subsidiarity contributes to the process of constitutional adaptation and federal system robustness.
\end{abstract}

Subsidiarity is, in a very real sense, the soul of federalism. Subsidiarity is the animating philosophy of the European Union, and it pervades the federalism doctrines of Canada and Germany (Føllesdol 1996, Hueglin 2000, Halberstam 2009). It is discretely, but no less powerfully, the vision

*Forthcoming (2014) NOMOS LV: Federalism and Subsidiarity, eds James E. Fleming and Jacob Levy. New York: NYU Press. I'm grateful to Jacob Levy for suggesting this essay's direction and to feedback from audiences at the University of Southern California Gould School of Law and the University of Chicago Law School. 
behind many other federations, including - the New Deal notwithstanding the United States. The federal system, with its layers of decision making, is the scaffold bearing the downward weight of this premise of decentralization. Federalism, in turn, is sustained by a system of safeguards.

But why presume decentralization - why value subsidiarity? Support for it is generally tied to two effects: better satisfying the preferences of a diverse population and promoting efficient use of taxes by creating a horizontally competitive environment (Tiebout 1956, Oates 1972). Oates prescribes subsidiarity as one of the tenets of fiscal federalism. His decentralization theorem states: "In the absence of cost-savings from the centralized provision of a [local public] good and of interjurisdictional externalities, the level of welfare will always be at least as high (and typically higher) if Paretoefficient levels of consumption are provided in each jurisdiction than in any single, uniform level of consumption that is maintained across all jurisdictions" (Oates 1972:54). In this issue, Calabresi and Bickford underscore this reasoning, calling it the "economics of federalism". As long as there are no policy spillovers, and as long as either people, firms, or capital can move, decentralization benefits society. Diverse, geographically clustered populations can create policy tailored to fit their own needs. And with a Tiebout mobile voter, local governments compete with one another for citizens (and their tax dollars), driving down the likelihood of corruption and other inefficient practices.

In these accounts, subsidiarity improves social welfare by satisfying diverse preferences and by encouraging efficient government. These are important features, but address only the immediate, and static, policy environment. The distribution of national and state authorities is calibrated to optimize social welfare. If the policy environment changes, then a different weighting of national and state authorities may better serve the public. A theory of authority assignment in federations should satisfy not just efficiency, but adaptive efficiency.

In this article I make the case for a third benefit of subsidiarity: it improves the adaptive efficiency of federal systems. In order to perform well over time and to recover from shocks and changing circumstances, federations must adapt. Adaptation requires exploration of the boundaries of federalism and a system of diverse, complementary safeguards to determine whether alterations to the boundaries represent improvement. Subsidiarity contributes to that process in two ways: it diversifies the constitutional modifications tested and it increases the range of interpretive signals used in judging the 
advantage of the modifications.

In this article I will lay out the model of federal robustness and then in separate sections describe subsidiarity's two roles in constitutional adaptation: through policy subsidiarity, it can promote experimentation, and through safeguard subsidiarity it multiplies the perspectives that judge the acceptability of new policies, reducing the likelihood of harmful authority migration. The article offers a positive justification for subsidiarity, invoking a theory of system robustness and adaptive efficiency.

\section{Robust Federal Design}

A constitution is a system blueprint; the government that it creates is composed of intersecting components shaped by the constitution, but with an effect that can only be understood in situ (Vermeule 2009, 2011, Bednar 2009). It is akin to the DNA of an organism or the recipe for a cake. Like a recipe or a genetic string, every constitution has components, each with an identifiable effect. Constitutional components include the legislature, executive, judiciary, electoral system, expressed rights, etc, as well as the auxiliary institutions the constitution endows through these components: lobbyists, political parties, and the media.

One feature of systems-level approaches is captured by the phrase "the sum is greater than the parts." While each component of a system has identifiable properties, their effects may not be independent of other components. Instead, the role played by one component is either augmented or diminished by the presence of another component. As a result, the system's properties and functionality cannot be inferred from the properties of any one component. For example, Vermeule (2009) points out that although the U.S. Supreme Court has countermajoritarian properties that make it, on its face, contrary to democratic principles, the presence of an independent court empowered with legislative review enhances the democratic properties of the government. An unelected, countermajoritarian component makes the governmental system more democratic, not less so. When the component's effects are so interlaced, to understand the effect that any one has, one must study the whole as a system.

Federalism adds complexity to a democratic governmental system. Each level of government, national and state, has its own set of components, and the authority to make laws or establish programs is distributed between the 
levels. There is also a possibility of shared authority. This distribution is set constitutionally, with broad parameters established formally through enumeration of powers written into the Constitution itself. But constitutions are a combination of the written words and the conventions, established through practice, that illuminate and extend them. In that unwritten constitutional culture, further assignment of authority may be located.

This added complexity makes possible some functionality that is more difficult to achieve in a unitary system. Madison believed that federalism would enhance democracy by introducing further checks to prevent autocratic control. ${ }^{1}$ Weingast (1995) argues that federalism preserves markets when federal and state budget making are separated and each has a distinct role in preserving the common market. And most intuitively, by distributing authorities between the national and state governments, a federal constitution enables local control, the subsidiarity invoked by Hayek (1960) and Oates (1972).

The distribution of authority - what is often referred to as the boundaries of federalism - is our subject of interest because this distribution determines the capability of a federation. The combination of decentralization and centralization enables a society to enjoy a common market, security, and political accountability while affording local adjustments to suit diverse tastes. It is the control dial of federalism. The balance of national and state authorities affects how well the federal government - the union of national and state actions-serves the people.

Given this purpose of federal systems, we become interested in the federation's ability to maintain that functionality over time and the role played by the constitution in assisting that end. Robustness is an enviable property of any system, whether it be engineered, ecological, or legal. Formally defined, robustness is the capacity of a system to function despite perturbations (Jen 2005). A robust system is not derailed by disturbances, whether they be short-term or permanent redefinitions of the environment. In the federal system, these disturbances may be exogenous shocks such as fluctuations in the global trade environment, or they may come from internal dynamics, like the unforeseen rise of the tea party movement. The ability of the federal system to fulfill its purposes should not depend on vagaries such as which political party is in office or fail due to scandal in a politician's personal life.

Redundancy and self-regulation are properties of robust systems. Robust

\footnotetext{
${ }^{1}$ See for example Madison's arguments in Federalist 39, 46, and 51.
} 
systems are often overdesigned, with multiple components performing similar functions (Krakauer \& Plotkin 2004), such as oral communication accompanied by hand gestures to boost the fidelity of a signal's transmission (Ay et al, 2007). A robust power grid, with multiple pathways connecting all points, continues to supply electricity to all users when storms down lines or disable power stations. A robust system is also self-regulating. The well-designed power grid will reduce flow to certain users in order to maintain flow to others, using instruments such as discriminatory pricing during peak hours or with interruptible service to nonessential devices such as water heaters.

Robust systems are also capable of adaptation. The process is slow, purposefully so. Rapid mutation, if irreversible, may cause systems to overreact to short-term fluctuations when the original configuration might perform better in the long run. For short-term challenges, redundancy, excess capacity (which is a form of redundancy), and regulation support the system's robustness without requiring the system to change. Nevertheless, some environmental change is permanent, and a robust system accommodates that change with its own adaptation.

The policy environment is dynamic, but unlike some dynamical systems, it is not homeostatic; it does not hover around a constant state. It is not a heating and cooling system, regulated through a thermostat, that keeps a room's temperature at a constant seventy-two degrees. Instead, its mean value, if you will, is slowly changing. All policy inherently involves compromise - trading equity against liberty, infrastructure investment against personal savings, common standards against diversity and innovation, short-term advantage against long-term stability, group versus individual rights. The socially preferred compromise point varies over time.

The variation in socially preferable policy can come from any number of environmental sources, from technological innovation to ethical perspectives. Advances in pharmaceutical technology, leading to the opportunity for birth control, leave couples vulnerable in states with moral opposition to interference with conception. A diminishment in the salience of race and a moral sense of human universality cause fresh national dissatisfaction with discriminatory employment, voting, or marriage rights. In the face of these dynamics, existing national values, expressed in the Constitution, can be reinterpreted to be applied to new situations, leading to a disallowance of long-established state policy on constitutional grounds.

One common way that the environment changes is the extent that a state's policy generates externalities. While winds aren't blowing any more 
strongly these days than they used to, so in that sense the environment is unchanged, they are carrying more pollutants than before. Industrialization and manufacturing developments, population growth, and higher per capita energy demands are processes that cause larger quantities of sulfur dioxide to be released into the air than can be absorbed naturally, leading to acid-laden rainfall in eastward states. If the externalities are negative-if the policy spillovers are harmful to residents in other states - then outright centralization may be warranted, or a method of concurrent regulation that generates incentives for the states to change their policies, such as conditions on federal spending.

Externalities can also be positive. A state offering health care or university education to a population that might very well move out of state are two examples. If the policy is costly - as health care and education are - then the national government can offer incentives (shared costs for Medicaid), create standards (requiring school performance measurement and setting common goals of literacy), or invest in the program to reduce its cost (sponsored university research, guaranteed student loans, Pell Grants and other student aid). Federalism's layers provides a method for encouraging socially productive policies that otherwise might be deemed too costly to undertake (Bednar 2011).

Whether the imperative is increased externalities, changing moral beliefs, or economic downturns, the policy environment fluctuates, sometimes in the short term, but sometimes permanently. Now that Americans have discovered the road, and own cars, they are not going to stop using the interstate transportation network. Just as the federal government made the train network possible by purchasing vast tracts of land that it essentially ceded to private railroad companies, the federal government built and helps to maintain the highway system and contributes significantly to air transportation. Future transport will use means we haven't yet imagined, and the relative involvement of the national and state governments in transportation policy may change yet again.

As the nation's goals evolve and the policy environment changes, sometimes the distribution of authority between national and state governments will be more efficient if it is adjusted. It may be centralized or decentralized, or the extent of the shared authorities may be recalibrated, either further extending concurrent powers or by granting one level exclusive authority. When the efficacy of the balance of authority changes, the federal system ought to be responsive if it is to remain robust. A robust federation adapts. This 
claim leads to a question: What is the process of constitutional evolution?

As an initial model of constitutional adaptation, it is a fair approach to consider the processes that contribute to adaptation in biological systems. Organisms evolve through a process of genetic mutation, heritability, and sexual selection. "Innovations" are introduced randomly; some are culled during the reproductive process and then passed on to offspring. Thereafter sexual and environmental competition ensures that only the fitness-enhancing mutations continue to spread through the population. Biological adaptation is a process of trial and error; key to the search for improvements to the organism is the trial of many changes and a multifacted selection process that gives diverse new forms a chance to prove themselves in the environment.

In contrast, formal constitutional amendment procedures are tightly constrained, admitting little change. In comparison with biological systems, they are overselective. Formal constitutional amendment in the U.S. system, as in many other federal systems, requires a supermajority assembled several different ways. It is a process reserved for policy or institutional modifications that have already acquired widespread support. Given that support often requires experience, to grow comfortable with the idea, it is not hard to surmise why there have been so few amendments to the US Constitution since its adoption. ${ }^{2}$

Given the difficulty of formal amendment, reinterpretation of the existing rules is the primary means of constitutional adaptation. This reinterpretation does happen in court decisions, as one's intuition would anticipate, but by the time a query reaches the courtroom, many steps in the process have already been taken. Mutation and selection, the main adaptation mechanisms from biology, are at work in legal evolution as well.

Subsidiarity plays a key role in both mutation and selection. Subsidiarity predisposes the system toward decentralization, and with decentralized authority, more governments have an opportunity to modify existing policy, either through setting their own or by adjusting the implementation of federal policy. And the selection mechanism is the set of safeguards, the combination of formal and informal institutions that review government policy, making a determination of its appropriateness. Although the role played by subsidiarity is less intuitive in this part of the adaptive process, it is no less

\footnotetext{
${ }^{2}$ Formal amendment procedures can also be too loose. While the topic extends beyond the scope of this article, it may be that the motivation to adopt loose amendment procedures fails to appreciate the possibilities of informal amendment.
} 
important than with mutation, or policy innovation. In the next two sections I describe the assistance that subsidiarity provides in both innovation and selection, thereby contributing to the adaptive efficiency of the federal system.

\section{Policy Subsidiarity}

Policy subsidiarity, where policy authority is set at the lowest competent level of government, is conventionally justified for two reasons: it provides the opportunity to satisfy locally divergent preferences and it promotes efficient government. Policy subsidiarity lets locally diverse populations devise policy that fits their own, specialized preferences. Tiebout (1956) explains how it also puts governments in competition with one another, as citizens can move around a region, "shopping" for a government that best matches their needs. The mobile voter puts governments in competition with one another, motivating them to provide services most efficiently, at lower (tax) cost to the residents.

Both justifications are commonly invoked and intuitively appealing. However, when combined - and they quite regularly appear in the same sentencethey present a paradox: they work against one another. In order to promote efficiency, the local governments must be in direct competition with one another for mobile voters, firms, and capital, and therefore must be substitutes, fully comparable in every dimension, like gas stations or fruit vendors, competing on price. But the lack of differentiation means that they are not catering toward particular categories of voters or capital. The more that governments specialize by offering distinct services - satisfying divergent preferences - the less that competitive forces drive them toward efficiency.

Sidestepping the contradiction of the two conventional justifications, here I offer a third claim: policy subsidiarity promotes adaptive efficiency. In order to adapt, systems must learn more about their environment, generally through experimental mutation. However too much experimentation or pursuit of new information can be inefficient when the system fails to use existing information. With adaptive efficiency, the system balances regularity with experimentation, whether the application is machine learning (Holland et al 1962, Holland 1992), phenotypical consistency in biology (Fisher 1930, Krakauer 2006), or standard operating procedures in organizational culture (March 1991). Given that a system cannot simultaneously exploit current 
best practice and conduct trials of new practices designed to reduce the error in existing practice, a robust adaptive system will have an internal regulator that allocates some energy to maintaining regularity while some subset of the system conducts trials.

In addition to dedicating energy to exploration, the system will seek $d i$ verse new information. The more diverse the experimentation, the more likely the system will encounter a modification that improves it. This insight was first articulated by evolutionary theorist R.A. Fisher, who noted that the "rate of increase in fitness of any organism at any time is equal to its genetic variance in fitness at that time" (1930:37). This claim, known as Fisher's fundamental theorem, suggests that biological organisms depend on genetic variation to survive complex environments. In social systems, the more a system is able to incorporate diverse ideas, the more likely it is to discover better solutions to problems (Page 2007, 2011).

The structural features of federal systems are ideally suited to meet both criteria of adaptive efficiency. Experimentation is a useful way to explore the policy space, to determine whether any change to the distribution of authority might be welfare-enhancing. Rather than a single government modifying its policy, if policy is decentralized, then some governments may continue with established practice while others experiment. And rather than conduct single experiments, the variety of states and municipalities guarantees that different policies will be tried. Subsidiarity is the catalyst that boosts the likelihood of this experimentation: it is Brandeis' vision of the states as policy laboratories. ${ }^{3}$

Experimentation can take several forms. In the first instance, it is the creation of new laws or programs. When a problem is new, these proposals represent an initial solution, for example municipality-sponsored Internet access or creation of the Department of Homeland Security in response to domestic acts of terrorism. Experimentation also comes with a novel approach to an old problem, such as a bag tax for plastic bags in an effort to reduce roadside waste, or charging in-state tuition to undocumented immigrants.

\footnotetext{
${ }^{3}$ Justice Brandeis makes this argument in New State Ice Co. v.Liebmann, 285 U.S. 262 (1932). Kollman, Miller, and Page 2000 derive conditions where decentralization is preferable to centralized policymaking in solving difficult problems. The benefits of decentralization increase and then decrease as problem difficulty increases. They consider only a fixed environment. With a dynamic, complex environment, such as considered in this article, and a cost for policy modification, decentralization will be beneficial for a greater range of the policy environment.
} 
Experimentation can come from tweaking existing policies; raising expectations on standardized tests in Michigan, or California, in its perennial battle against smog, requiring that a percentage of vehicles sold to be zero emission. Nearly all new legislation explores the policy space; even if a state adopts another state's legislation in full, the new state's distinct context means that society learns something new about the effect of policy as it moves to a new environment.

Experimentation also comes during implementation because the agency charged with executing the law may interpret the law differently from other agencies, including having different standards for enforcement. The state agencies that enforce the Environmental Protection Agency's standards notoriously differ significantly in the extent to which they search for violations, and even in the extent to which they prosecute violations once identified. When authority is shared between national and state governments, states have many opportunities to put their own imprint on federal legislation, and those distinct imprints become experimentation.

Some of this experimentation occurs within the existing distribution of authority, but some of it pushes against existing understandings of the national/state balance. To improve access to health insurance, Congress introduced two innovations: require everyone (with some exceptions) to carry insurance, and set a common floor for Medicaid eligibility thresholds. Both innovations represent a shift in the national/state balance. In another example, to address the policing challenges created by the presence of undocumented residents, Arizona rewrites its police procedures in a way that claims responsibility for immigration policy. While not every experiment will stand scrutiny - that is the subject of the next section - this pressing against the boundaries tests the existing balance of responsibilities.

Policy subsidiarity's role in promoting experimentation is straightforward. It tips the scale of responsibility toward the states and localities. It gives them more opportunities to experiment, and also gives them a pass to wander into new policy domains, so that they need less justification for experimentation. In a federal system, policy experimentation can be judged both horizontally, comparing one state's policy to another, and also vertically, where the state and the federal government may compete in the same policy space with rival proposals. By preferencing decentralization, experimentation is far more likely, and more likely to be useful. 


\section{Safeguard Subsidiarity}

Safeguard subsidiarity is as unknown to scholars of federalism as policy subsidiarity is familiar. With safeguard subsidiarity, the network of institutions that review the constitutionality of policies is as decentralized as feasible. Given that this concept is less familiar, I divide this section into three subsections. I first review the theory of federal safeguards, then describe the theory of complementary safeguards, where safeguards are not independent contributors to federal robustness but instead are interdependent (Bednar 2009). Finally, I describe how subsidiarity augments the performance of the system of safeguards.

\subsection{Safeguards as Selection Mechanisms}

While broad experimentation is useful, any ultimate alteration to the distribution of authority between federal and state governments should not happen randomly. It is far too likely that the collective action problems inherent to the federal union will lead to more harmful changes than beneficial ones. With policy subsidiarity, one might be concerned that federations would overinnovate, to the detriment of the union. To regulate authority migration, federations have a system of safeguards.

All adaptive processes require a selection mechanism to maintain system efficiency (Axelrod and Cohen 2000). In biology there are many different selection mechanisms, ranging from incompatibility with life to interspecies competition. One biological analogy that fits constitutional evolution well is the immune system. Consider what the immune system must do. It is entirely a part of an organism; its own survival, if you will, is dependent upon the survival of its host. No part of it is external to the system (here we set aside vitamin pills and antibiotics!). Upon encountering a foreign matter in the system that it hasn't seen before - some new protein in the bloodit must decide whether it is friend or foe. It doesn't have a consciousness, obviously, and so is not acting rationally or deliberately. Instead, it first responds nonspecifically, with the innate immune response, including fever and inflammation. Jawed vertebrates have a more complex, layered immune system, including an ability to adapt an antibody to lock on to the new matter, neutralizing it, so that the blood and organs can flush it out of the system innocuously. With acquired immunity, beneficial proteins are accepted and absorbed while harmful ones are flushed out. Memory cells 
retain the adapted antibodies, so that the next time the system encounters the same pathogen, it responds quickly, preventing disease. The system is self-regulating.

Constitutions have an immune system equivalent: safeguarding institutions designed to monitor and constrain the government from actions that run contrary to the goals of society. Intuitively, when one thinks of a regulatory mechanism-about interpreting and upholding the constitution, the function of a safeguard - one thinks of the judiciary. The court system hears disputes and renders judgments; at its highest level, the constitutional court deliberately reviews governmental action against the constitution to determine acceptability. It is this overt act of constitutional review, combined with the Court's power to annul a legislative act outright, that makes the judiciary the conspicuous safeguard.

Despite its salience, the judiciary is far from the federal system's sole defense. Many other safeguards operate in a constitutional system. Madison praised the structural safeguards: the checks and balances of the fragmented and interdependent national government, as well as the incorporation of the states into the federal decision-making apparatus (Bednar 2003); Weschler (1954) highlighted state incorporation as well as the informal network of lobbyists and state representatives that pressed state interests at the national level (he called these political safeguards). ${ }^{4}$ An integrated party system creates a political reliance between elected officials at the state and national levels (Filippov, Shvetsova, and Ordeshook 2004), and the state agencies, armed with their charge of executing national law, sometimes actively resist implementation (Bulman-Pozen and Gerken 2009) but more often simply use their discretion to suit their own capacities and interests, or assert their interests effectively in negotiating authority (Ryan 2011, 2012). Finally, the public, through a cultural sense of balance between the levels, approves or disapproves of governmental action (Tushnet 1999, Mikos 2007).

In light of these alternative safeguards, it is not clear that the judiciary even ranks as the federation's primary regulatory mechanism. In terms of chronology, the judiciary is nearly always one of the later safeguards to act, simply because of the way that the judiciary is structured. In many constitutional systems, including the United States, the Court will not engage a

\footnotetext{
${ }^{4}$ See also Nugent 2009, tracing the deep involvement of state officials in setting congressional policy, and Schapiro 2009, arguing that the recognition of rights involves national and state dialogues.
} 
question of law until one party has sustained an injury. In some constitutional systems, such as Canada, a government may reference a question of law to the Supreme Court prior to the law's adoption, but the reference is exceptional. As a matter of routine, judicial review is subsequent to other safeguards permitting the action or being insufficiently powerful to check it.

Despite their variety of forms, each of these safeguards behaves as a selection mechanism: it draws its own line defining (constitutionally) acceptable practice - often, this line is implicit and unannounced (and in most cases, is not a conscious determination by the safeguard); it makes an observation about the policy or practice, and it renders a judgment, comparing its threshold and its observation. Protection is also about interpretation, not just about defending the boundary but about drawing it. If the observation fails the safeguard's standards of acceptability, it punishes in whatever manner it can. Structural safeguards vote against a law; political safeguards use their political networks within the party organization to counter the proposed legislation; the judiciary strikes the law. Each acting in its own way, each safeguard is a component of the federation's regulatory system, halting destructive practices while allowing beneficial experimentation.

\subsection{Complementary Safeguards}

It is one thing to identify different safeguards of federalism, and quite another to consider how they fit together. Just as the heart is an essential but interdependent part of the human organ system, or the pistons are part of an engine, while each component might be physically separable from other parts of the system, each could not function without the other components. If one is interested in system-level properties - rather than asking how steady a heartbeat is or how efficiently a piston fires, but instead how healthy the person or how fast a car goes - then one must consider the components together.

System effects characterize the way that the components interact to generate positive or negative feedback. Given the collective action dilemma inherent to federations (Dougherty 2001, de Figueiredo and Weingast 2005, Bednar 2006, 2009), the union will tend to generate negative externalities. Whether or not the federation surmounts that tendency - whether the states make one another better off rather than worse off-depends upon the effectiveness of federalism's subsystem of safeguards. We can ask: Under what conditions are the components of the federal regulatory system likely to gen- 
erate positive feedbacks for one another? That is, what makes them complementary ${ }^{5}$

The key insight in the hunt for complementarity is that there is no such thing as a perfect safeguard. "Perfection" in constitutional review is illdefined. One might strive for an ideal type of safeguard, one that always identifies the true meaning of the constitution. But constitutional truth is subject to interpretation, and despite admirable efforts to deduce it, the fact remains that multiple interpretations of its meaning persist. Rather than wander into the path of the friends or foes of a living constitution, this essay takes a different turn. Complementarity matters because no safeguard on its own is sufficient. Each safeguard is incomplete, and each is an imperfect monitor.

Completeness refers to any one safeguard's ability to regulate all governments within the federation, and all actions that each government might take. Most discussions of subsidiarity seem uniquely concerned that the federal government might encroach on state domain. But given that subsidiarity recommends decentralization to the lowest competent government, states can assert themselves inappropriately as well. In order for a safeguard to be effective, it must be able to end noncompliant behavior (and, preferably, to be able to preempt most unproductive, noncompliant behavior just by its presence). The implication is that the safeguard must be deemed legitimate by all parties.

In considering whether the Court, for example, is a complete safeguard, one must then ask whether its judgments carry sufficient weight that every government within the federation will respect its decisions and cease their challenged policies. In the American system, the Supreme Court has carved out a position of significant legitimacy and the stature to be able to review the constitutionality of federal and state action, largely by remaining in sync with the public (Friedman 2009). One hypothesis of how the Court built its federalism legitimacy is that in the early days it focused its constitutional review authorities on state actions. Over time, the public grew accustomed to its review power, and it was able to exercise its authority against the national government (Friedman and Delaney 2011). In Canada, the story is different. The Court has always been viewed with deep suspicion by the provinces (Hogg 1979, Smithey 1996). The canadian Supreme Court is an

\footnotetext{
${ }^{5}$ The theory of complementary institutions that I describe here is extracted from Bednar 2009.
} 
incomplete safeguard: it has a harder time maintaining its legitimacy -its authority base - while striking provincial law.

Imperfection, in contrast, focuses on procedural deficiencies: judgments skewed by infidelity in the different sources of evidence lead some safeguards to consider dimensions that other safeguards ignore, and and inflections in the structure of the decision-making process or the influence of private motivations that cause two safeguards to read the same evidence differently. In this positive sense no safeguard is perfect. No safeguard views the whole of any dispute.

One way that safeguards are imperfect is in the neutrality of the evidence it hears. In standard political economy models with imperfect information, the signal — for us, the safeguard's read of the public policy — is noisy. There is an imperfect correspondence between the true message and the way that it is received. However, in standard political economy models, the noise is not related to the observer, just as the diffusion of light is not affected by one's eyes taking it in. The distortion is generated by the informational source, such as an ambiguously written legislative text.

A different way of thinking about noisy signals is to recognize that each observer has her own perspective which can distort that signal, just as myopic lenses affect the clarity of one's view. This alternative model of imperfect information, interpretive signals theory (Hong and Page 2009), returns the modeler's attention back to the subject who is making the observation. Different agents would perceive different implications of the same law not (solely) because of the law's inherent ambiguity but because each agent has characteristics that shape the way it reads the law. In the federal system, each safeguard looks at different evidence or views the same evidence through different criteria - sometimes political expedience, sometimes policy efficiency, sometimes legal reasoning. The safeguards are diverse in procedure, diverse in evidence considered, diverse in interests, diverse in the threshold they draw between acceptable and unacceptable practice.

A second source of imperfection relates to the high dimensionality of public policies. Each safeguard may observe (or pay attention to) only a subset of a policy's attributes. If the safeguards pay attention to different attributes, then the more diverse the safeguards, the more likely that, as a system, the safeguards will take all attributes into consideration when judging the acceptability of a policy. This form of imperfection is different from the first in that the uncertainty does not come from distortion but instead from any one safeguard's limited view. With both sources of imperfection the 
result is the same: different safeguards will tolerate different practices.

This final point - that different safeguards would tolerate different policieswould seem to be a violation of of the essential foundation of the rule of law, which calls for a consistent interpretation of the law, objectively applied. Given that each safeguard is flawed, one might ask: Why compound the problem with multiple safeguards?

Multiple safeguards are better than one when they fail for different reasons. Failure - accepting harmful new policies or rejecting beneficial onesresults from errors in judgment, and errors, applying the interpretive signals theory, are a product of an agent's perspective. Therefore, different perspectives lead to different sources of failure. If no safeguard has the final word, but several have an opportunity to review new policy, then the safeguards operate as a system. The more uncorrelated their errors - meaning the more uncorrelated their perspectives - the less likely it is that the safeguards, as a collective, will fail. Complementary safeguards are diverse.

No single safeguard is sufficient. Each is limited in its reach, whether culturally, politically, or legally, and each has a biased view of the evidence regarding a policy's constitutionality. Effective, flexible maintenance of the boundaries of federalism cannot rely on any one safeguard, whether it be the court or the party system. Instead, robust federations rely on a system of safeguards, and the more diverse the safeguards, the more they complement one another. Each is imperfect, but because they are diversely imperfectflawed in different ways - the system as a whole is more perfect.

\subsection{Subsidiarity Multiplies Perspectives}

With the theory of complementary safeguards in hand, and paying particular attention to the multiplicity of perspectives, we are now prepared to consider what effect subsidiarity has on federal system robustness. In the system of safeguards, subsidiarity will be valuable if it increases the complementarity between the safeguards. One intuitive contribution is that it improves monitoring. I am skeptical. In this subsection I will lay out a different case for subsidiarity: safeguard subsidiarity affects both the organizational structure and the personnel within it, and both effects will diversify the safeguards.

The conventional defense of subsidiarity is that decentralizing policy making reduces the costs of monitoring. A safeguard depends upon the quality and completeness of its information in order to make good judgments about the acceptability of governmental actions. It is commonly understood that as 
monitoring costs increase the performance of a regulatory system decreases. Small-scale organizations generally are able to induce more collective action because the agents all know one another and can directly observe whether one is shirking. In addition to knowing whether one's neighbor is pulling his weight, members of small-scale organizations know one another well enough to be able to be flexible when someone fails to meet expected effort - for example, because of trouble at home, or because of effort elsewhere, say through volunteering (Ostrom 1990). Impersonal organizations lack this knowledge and must make up for it through formal institutions. Optimal institutional design changes with scale because of the difference in information available.

Given the usefulness of personal information, it seems intuitive that subsidiarity, with its tendency toward decentralization, would improve monitoring by capturing local knowledge. The logic is right, but the empirical evidence is thin. The necessary smallness of scale turns out to be really small. As soon as scale expands to a community of strangers - which certainly is true by the time you hit the typical middle-sized town, such as Ann Arbor, Michigan - direct monitoring is unavailable, and the reach of personal networks is stretched thin.

Whether or not subsidiarity improves the safeguards' monitoring capacity, it bolsters the robustness of the system by multiplying the safeguards' perspectives. Recall that in a robust regulatory system the different components must fail for different reasons. Think again about the chronology. By the time the Court hears a case, the policy has already been accepted by many other safeguards. If the system is to avoid the Type I error - accepting what it should reject - the safeguards that precede the Court should focus on different aspects of a policy so that the errors are not correlated. To diversify these perspectives, an application of the principle of subsidiarity to the design of the federal system of safeguards operates on two dimensions: the organizational structure and the personnel who staff the safeguards.

Where policy subsidiarity decentralizes responsibilities to lower levels of government, safeguard subsidiarity decentralizes the forum for judging policy. Each component - the judiciary, the party system, and so forth-will have a hierarchical structure with the potential to decentralize decisions to lower levels. The U.S. federal system displays two good examples of safeguard subsidiarity in the organizational structure of its judicial and political safeguards. The judiciary is divided into two nearly independent systems: the state and the federal judiciary. Only at the highest appellate level are the two formally joined, and within the system, policy subsidiarity augments the 
status of state decisions, bleeding over into safeguard subsidiarity. Within the federal judiciary, the district courts are grouped into distinct appellate branches. One might imagine any number of ways to organize the appellate branches, from specialization by legal domain to a random assignment to balance dockets. Both would be designed with efficiency in mind. Instead, the appellate courts are organized geographically, a structural choice dating back to a time when judges would ride circuit, hearing cases throughout a territory defined by their horses' reach. This organizational form, privileging geospatial relationships, is true to the principles of subsidiarity. Whether its origins are calculated or serendipitous, this decentralization provides an opportunity for diverse interpretations to emerge through distinct legal cultures. Their coexistence offers a natural experiment of sorts, at least until the Supreme Court steps in to resolve the inconsistency.

Although less formally structured, the hierarchy within the American party system provides the same advantages. Local party organizations strike their own sets of priorities; at party conventions these separate policy priorities get aggregated. Sometimes the aggregation is a mere discovery of the national party median, but quite often national party platforms are an amalgamation of interests, manifestations of the vote trading that typifies political compromises.

Subsidiarity can also affect the staffing of the safeguards. Even though the institutions are structured differently, if they are all staffed by like-minded people they are far less likely to arrive at different conclusions. If all were raised by upper-middle class Democrats in established suburbs and attended Yale Law School before going into public service - a very common public servant's CV - the similarity of their shared experiences and education makes it likely that they will arrive at the same conclusion about evidence. If all were taught the same interpretation of the priveleges or immunities clause during their time at Yale, then they all become more likely to draw identical conclusions about the acceptability of new state policy governing citizen rights. The similar mind-set of these public servants reduces the institutional diversity of the safeguards.

Safeguard subsidiarity contradicts this potential flaw. In the U.S. system, safeguard subsidiarity influences the staffing of safeguards in several ways. In the judiciary, local and state judicial appointments and elections are largely free of national political influence. Appointments to the federal courts, although nominally in the president's hands, display deference to local and state interests through norms such as senatorial courtesy: the president 
seeks the advice of the state's senior senator when making appointments to the appellate bench or for district attorney. The political safeguards are diversified by the sheer number of local elections, which drives up the need for local political organizers with local knowledge. Rather than hiring a local campaign manager based upon the generic "quality" of her degree from a nationally ranked university, she is valued because she knows who to call, which local clubs are politically active, and where to send volunteers to knock on doors. In these cases, the influence of local interests shapes the perspectives of those who do the "judging" within the safeguards, determining what is an acceptable policy. We might also remark one change to the safeguards that arguably reduced diversity: the 17th amendment. By taking the appointment of senators out of the hands of state legislatures and giving them to the state's public to elect, the national party organization has a much greater opportunity to shape outcomes by financing its preferred candidates.

Federal systems have multiple safeguards: judicial, political, structural, and popular; each is imperfect. If they complement one another through their diversity, the system is more robust; it is less vulnerable to the failures of any one safeguard. It permits more mild experimentation while being more likely to catch destructive deviations. Safeguard subsidiarity improves their complementarity by further ensuring their diversity both through the organizational structure and in the people who staff the safeguards.

\section{Discussion}

In beautiful phrasing from Calabresi and Bickford (this issue), in allocating authority optimally between the two levels of government in a federation, we seek "a golden mean", a phrase that invites a vision of a sublime proportionality, a natural aesthetic for the relative jurisdictions of each level. A golden mean is also a fixed ratio, and so if we take the phrase literally, a static balance could be the doom of a federal system. Instead, a robust federation must adapt, which means that the balance between national and state governments may change over time. Subsidiarity is a catalyst for that change, empowering many more governments to explore the policy space to devise improvements to the balance, in both exclusive and shared authorities.

A presumption of subsidiarity bolsters the robustness of a federal system. Federalism can help a society achieve particular goals related to the economy, security, or representation, and the distribution of authority between the 
national and state governments is the instrument that federalism offers. This distribution of shared and exclusive authorities is protected by a system of formal and informal safeguards, from the judiciary to the political culture. Over time, the distribution will need adjustment to fit a changing political, economic, or social environment, raising the essential question for federal constitutional design: How can a system of safeguards be both rigorous and flexible?

In this article I laid out the case for subsidiarity's contribution to federal robustness. Federations must adapt to remain efficient, and subsidiarity contributes to two key aspects of adaptation: experimentation and selection. One of the key positive arguments for subsidiarity is that local governments can experiment; competitive pressures will lead all governments toward efficiency. Without a doubt, subsidiarity enhances such horizontal experimentation as it generates a tendency toward decentralization, necessary for horizontal experimentation. But neglected in the subsidiarity literature is the importance of vertical experimentation.

Vertical experimentation is the tug between the national and state governments for authority (or, less often, attempts to skirt responsibilities). Given that federal constitutions tend to tolerate a lot of shared authority, much experimentation occurs without changing the legal definition of the federal boundaries. States exercise more or less of their discretion, and the national government opens and preemption that boxes in state action. Sometimes this experimentation with the boundaries of federalism captures the attention of the judiciary, and when it does, it can transform the federation. Far more often it is the normal stuff of policy making in a federation. Nonetheless, it is important experimentation, and could not be possible without the decentralization that subsidiarity tends to bring.

Subsidiarity also boosts the second ingredient in federal adaptation: the selection process. Like a stretchy rubber band, the safeguards can accommodate significant experimentation, but at some point - not always predictablethey will reach their limit and disallow the changes to the federal distribution of authority. The Court's recent decision to strike the portion of the Affordable Care Act that mandated a minimal eligibility threshold for state participation in Medicaid was one (unforeseen) example of national government action pushing the boundaries too far. The theory of multiple and complementary safeguards is developed in Bednar 2009, but here, I describe how subsidiarity contributes to that system.

In the federal political system, information about the usefulness of pol- 
icy change comes from every agent who voices support or dissent. Drawing on Fisher, the experimentation ought to be diverse if the space of policy options is to be fully explored. The components of the federal system are diverse - with distinct interests, as with each state- but also with distinct perspectives. Sometimes that diversity is created through informational filters: the Court learns differently from agents in the political arena because of the rules defining what evidence it might consider. While these diverse entities experiment and judge that experimentation, a public dialogue emerges.

A robust system of safeguards will carry a plurality of perspectives to maximize the amount of information considered by the safeguards in judging governmental policy. Not only are the safeguards, whether judicial, political, popular, structural, or intergovernmental, diverse due to their structure, but aided by subsidiarity, they are diversified in composition as well. With elections, nominations, and appointments rising up from the lowest levels of government the polity maximizes the potential that the safeguards are staffed by people with diverse experiences, who would be more likely to see distinct aspects of the same case. Judging the appropriateness of legislative or executive action - whether literally as a jurist, or figuratively, as a partisan, or a voter - is akin to solving a problem by a team; the aggregate judgment is the group's determination of the optimality of constitutional adjustment. Diverse teams can be better problem solvers (Page 2006). This perspective diversity is most likely with subsidiarity. Subsidiarity does not just protect diverse interests; it protects diverse safeguards.

Subsidiarity is often praised for instantiating a toleration of difference. It is related to the european legal definition of the "margin of appreciation": some constituent units will have a different policy, and those differences will be tolerated, even if it is in tension with prevailing norms. Subsidiarity is not necessary for this toleration of difference. Given the inherent imperfection of federalism's system of safeguards, perfect compliance is not possible. With the margin of appreciation doctrine, one safeguard-here, a courtdetermines the standard as well as the acceptable margin. In the end, the result is the same; it is a single line drawn by a single referree; it just happens to be drawn more thickly, so that it tolerates different practices in different places.

The contribution of subsidiarity to federal system robustness is not (only) differences in practices, but different ideas about what practice is acceptable. It diversifies not only policy experimentation but the judgments by the safeguards, at least within a moderate band of experimentation. If the lower 
levels of government experiments, and if they have a role in staffing the various safeguards of federalism - both made more likely with subsidiaritythen the constitutional rules evolve not through central planning and formal amendment but more often through a bottom-up process of experimentation and acceptance. Rather than a single safeguard (or multiple safeguards with identical perspectives) proclaiming what deviations are acceptable, there is a possibility of disagreement between the safeguards. With disagreement can come dialogue, a citizenry engaged in consideration of constitutional adaptation. What subsidiarity-weighted federalism brings is not the "toleration of difference" - that is always present-but different tolerances.

\section{$5 \quad$ References}

Axelrod, Robert and Michael D. Cohen. 2000. Harnessing Complexity. New York: Basic Books.

Ay, Nihat, Jessica Flack, and David C. Krakauer. 2007. "Robustness and Complexity Co-Constructed in Multimodal Signaling Networks." Philosophical Transactions of the Royal Society B 362(1479):441-447.

Bednar, Jenna. 2003. "The Madisonian Scheme to Control the National Government," in James Madison: The Theory and Practice of Republican Government, ed. Samuel Kernell. Stanford University Press, pp. $217-242$.

Bednar, Jenna. 2006. "Is Full Compliance Possible? Conditions for Shirking with Imperfect Monitoring and Continuous Action Spaces." Journal of Theoretical Politics 18(3):345-373.

Bednar, Jenna. 2009. The Robust Federation: Principles of Design. New York: Cambridge University Press.

Bednar, Jenna. 2011. "Nudging Federalism Toward Productive Experimentation." Regional and Federal Studies 21(4):503-521.

Bednar, Jenna and Scott E. Page. 2007. "Can Game(s) Theory Explain Culture? The Emergence of Cultural Behavior within Multiple Games". Rationality and Society 19(1):65-97. 
Bulman-Pozen, Jessica and Heather K. Gerken. 2009. "Uncooperative Federalism." Yale Law Journal 118:1256-.

Calabresi, Steven G. and Lucy D. Bickford. Forthcoming. "Federalism and Subsidiarity: Perspectives from Law." NOMOS, this issue.

de Figueiredo, Rui J.P. and Barry R. Weingast. 2005. "Self-Enforcing Federalism." Journal of Law, Economics, and Organization 21(1):10335 .

Dougherty, Keith L. 2001. Collective Action Under the Articles of Confederation. New York: Cambridge University Press.

Fillipov, Mikhail, Peter C. Ordeshook, and Olga Shvetsova. 2004. Designing Federalism: A Theory of Self-Sustainable Federal Institutions. New York: Cambridge University Press.

Fisher, R.A. 1930. The Genetical Theory of Natural Selection. Oxford: Clarendon Press.

Føllesdal, Andreas. 1998. "Survey Article: Subsidiarity." Journal of Political Philosophy 6:190-218.

Friedman, Barry. 2009. The Will of the People: How Public Opinion Has Influenced the Supreme Court and Shaped the Meaning of the Constitution. New York: Farrar, Straus and Giroux.

Friedman, Barry and Erin F. Delaney. 2011. "Becoming Supreme: The Federal Foundations of Judicial Supremacy." Columbia Law Review 111(6):1137-1193.

Hayek, 1960. The Constitution of Liberty.

Hogg, Peter. 1979. "Is the Supreme Court of Canada Biased in Constitutional Cases?" Canadian Bar Review 57:721-39.

Holland, John H. 1992. Adaptation in Natural and Artificial Systems. Cambridge, MA: MIT Press.

Holland, John H., Burks, Arthur W., J. Willison Crichton, and Marion R. Finley, Jr. 1962. "Machine Adaptive Systems: Final Report." The University of Michigan College of Literature, Science, and the Arts, 
Communication Sciences Program, Office of Research Administration Project 05089 .

Hong, Lu and Scott E. Page. 2009. "Interpreted and Generated Signals." Journal of Economic Theory 144(5): 2174-2196.

Hueglin, Thomas O. 2000. "From Constitutional to Treaty Federalism: A Comparative Perspective." Publius 30(4):137-153.

Jen, Erica. 2005. "Stable or Robust? What's the Difference?" Robust Design: A Repertoire of Biological, Ecological, and Engineering Case Studies, Erica Jen, ed., Oxford University Press, pp. 7-20.

Kollman, Ken, John H. Miller, and Scott E. Page. 2000. "Decentralization and the Search for Policy Solutions." Journal of Law, Economics, and Organization 16(1):102-128.

Krakauer, David C. 2006. "Robustness in Biological Systems: A Provisional Taxonomy." Complex Systems Science in Biomedicine, Thomas S. Deisboeck and J. Yasha Kresh, eds. New York: Springer US, pp. 183-205.

Krakauer, David C. and Joshua B. Plotkin. 2004. "Principles and Parameters of Molecular Robustness," in Robust Design: A Repertoire of Biological, Ecological, and Engineering Case Studies, Erica Jen, ed., Oxford University Press, pp. 71-103.

Madison, James. 1961. "Federalist \#39, \#46, and \#51" in The Federalist Papers, ed. Clinton Rossiter. New York: New American Library.

Mesoudi, Alex. 2011. Cultural Evolution: How Darwinian Theory Can Explain Human Culture 83 Synthesize the Social Sciences. Chicago: University of Chicago Press.

Mikos, Robert A. 2007. "The Populist Safeguards of Federalism." Ohio State Law Journal 68:1669-.

Nugent, John D. 2009. Safeguarding Federalism: How States Protect their Interests in National Policymaking. Norman, OK: University of Oklahoma Press. 
Oates, Wallace E. 1972.

Ostrom 1990.

Page, Scott E. 2007. The Difference: How the Power of Diversity Creates Better Groups, Firms, Schools, and Societies. Princeton, NJ: Princeton University Press.

Page, Scott E. 2011. Diversity and Complexity. Princeton, NJ: Princeton University Press.

Ryan, Erin. 2012. Federalism and the Tug of War Within. New York: Oxford University Press.

Ryan, Erin. 2011. "Negotiating Federalism." Boston Law Review 52(1):1136.

Schapiro, Robert A. 2009. Polyphonic Federalism: Toward the Protection of Fundamental Rights. Chicago: University of Chicago Press.

Smithey, Shannon. 1996. "The Effects of the Canadian Supreme Court's Charter Interpretations on Regional and Intergovernmental Tensions in Canada." Publius 26(2):83-100.

Tushnet, Mark. 1999. Taking the Constitution Away from the Courts. Princeton, NJ: Princeton University Press.

Vermeule, Adrian. 2009. "System Effects and the Constitution." Harvard Law Review 123(1):4-72.

Vermeule, Adrian. 2011. The System of the Constitution. New York: Oxford University Press.

Wechsler, Herbert. 1954. "The Political Safeguards of Federalism: The Role of the States in the Composition and Selection of the National Government." Columbia Law Review 54:543.

Weingast, Barry R. 1995. "The Economic Role of Political Institutions: Market-Preserving Federalism and Economic Development." Journal of Law, Economics \& Organization 11(1):1-31. 
Young, Ernest A. 2012. “'The Ordinary Diet of the Law': The Presumption Against Preemption in the Roberts Court." Supreme Court Review Vol. 2011-2012:253-344. 